Research Paper

\title{
High serum Androgen and Insulin concentrations increase the tendency of Endometrial Carcinoma
}

\author{
Fei Teng ${ }^{*}$, Xiaotong Ma*, Xiaopei Yu, Ye Yan, Jing Zhao, Jinping Gao, Chao Gao, Yingmei Wang ${ }^{\bowtie}$, Wenyan \\ Tian $^{\bowtie}$ and Fengxia Xue ${ }^{\bowtie}$ \\ Department of Gynecology and Obstetrics, Tianjin Medical University General Hospital, Tianjin, China. \\ *These authors contributed equally to this study. \\ $\triangle$ Corresponding authors: Yingmei Wang, MD, PhD; Wenyan Tian MD, PhD and Fengxia Xue, MD, PhD. Department of Obstetrics and Gynecology, Tianjin \\ Medical University General Hospital, 154 Anshan Road, He Ping District, Tianjin, 300052, China. Phone: 0086-22-60363762, Fax: 0086-22-60362636. E-mail: \\ wangyingmei1978@126.com (Y. Wang), tianwenyan1108@163.com (W. Tian) and fengxiaxue1962@gmail.com (F. Xue).
}

(1) The author(s). This is an open access article distributed under the terms of the Creative Commons Attribution License (https://creativecommons.org/licenses/by/4.0/). See http:/ /ivyspring.com/terms for full terms and conditions.

Received: 2020.03.27; Accepted: 2020.07.16; Published: 2020.07.25

\begin{abstract}
Purpose: The objective of the study was to evaluate the important role played by androgen and insulin in the development of endometrial carcinoma (EC), and their combined effect on EC risk.

Methods: We enrolled 510 type I EC patients and 510 age-, time-, and nationality-matched subjects into this study. Metabolic and hormonal parameters of enrolled subjects were examined. Univariate and multivariate logistic regression analyses for EC and control subjects were performed. Type I EC risk was evaluated with respect to testosterone, androstenedione, and insulin levels based on odds ratios (ORs) using stratified data.

Results: EC risk was positively associated with C-peptide, estrone, androgen (including testosterone and androstenedione) and insulin levels, BMI, WHR, family history of cancer, nulliparity, irregular menstruation, diabetes, and hypertension. In multivariate logistic regression models, high C-peptide and testosterone levels, diabetes, and hypertension were independent risk factors after adjustment for BMI, WHR, family history of cancer, high serum insulin, and estrone levels. Increased serum total testosterone and insulin levels were positively correlated with EC risk in total, premenopausal, and postmenopausal women. Androstenedione was correlated with EC in total and postmenopausal, but not in premenopausal subjects. Compared with higher testosterone and insulin, odds ratios (ORs) for higher testosterone with lower insulin and lower testosterone with higher insulin were decreased in total, premenopausal, and postmenopausal women. Similarly, compared to both higher FAI and insulin, ORs for higher FAI with lower insulin and lower FAI with higher insulin were decreased in all three groups. Coordinately, ORs for higher androstenedione with lower insulin and lower androstenedione with higher insulin were decreased in total and postmenopausal, but not premenopausal subjects.
\end{abstract}

Conclusions: These findings suggested that androgen and insulin were risk factors of type I EC, and relatively high levels of both testosterone and insulin synergistically affected EC risk.

Key words: endometrial carcinoma (EC); testosterone; androstenedione; insulin; cancer risk

\section{Introduction}

Endometrial carcinoma (EC) is one of the most common malignant tumors of the female reproductive system and accordingly is a severe threat to female health. Its prevalence has increased yearly in the United States, and it is estimated that by the end of 2019, new cases of EC will reach 61,880 [1]. Similar trends have been observed in China [2].

In the past 30 years, EC has been broadly classified into two subtypes on the basis of histo- logical characteristics, hormone receptor expression, and grade. Type II EC are described as nonendometrioid, high grade, aneuploid, hormonereceptor negative tumors that are associated with a higher risk of metastasis and a poor prognosis. In contrast, the most common type I EC are thought to represent estrogen driven mostly by low-grade, hormone-receptor-positive, endometrioid tumors strongly associated with obesity and other 
components of the metabolic syndrome. It is generally acknowledged that the main internal secretion factor leading to type I EC is estrogen; the over-stimulation of endogenous and/or exogenous estrogen facilitates the abnormal proliferation of the endometrium [3]. Estrogen mediates endometrial cell growth, proliferation, apoptosis inhibition, and angiogenesis in vitro and in vivo by activating estrogen receptors (ERs) and downstream signaling pathways [4]. Progesterone counteracts the effects of estrogen (i) by inhibiting ERa expression, (ii) by preventing stromal production of growth factors and subsequent transcription factor activation [5, 6], and (iii) by inducing apoptosis in endometrial epithelial cells via progesterone receptor (PR) action in stromal cells [7]. Therefore, the deficiency of endogenous progesterone levels and diminished length of lifetime progesterone exposure are associated with the development of endometrial hyperplasia and an increased risk of type I EC [8].

It has also been reported that the morbidity of type I EC is associated with diabetes, hypertension, obesity, and polycystic ovary syndrome (PCOS), and these diseases (or risk factors) all are related to metabolic syndrome, which includes insulin resistance as a pathophysiological basis. Under conditions of insulin resistance [9], target organs tend to be insensitive to insulin, leading to increased levels of blood glucose, which makes $\beta$ cells constantly secrete insulin and C-peptide, and triggering the rise of plasma insulin and C-peptide levels. Although insulin and C-peptide are secreted in equimolar amounts, C-peptide has a longer half-life than insulin and its circulating levels are subject to less fluctuation. Thus, C-peptide is considered to be an indirect indicator of insulin secretion. Hyperinsulinism plays an important role in carcinogenesis as it potentiates mitotic activity in the glands and stroma [10, 11]. Moreover, insulin binding sites are also found in the endometrial stroma of women with EC [12]. Therefore, excessive insulin signaling can result in endometrial changes, similar to the effects of unopposed estrogen. In addition, a higher level of insulin can facilitate the synthesis of androgen [13], which can be converted into estrogen by peripheral conversion under the action of aromatizing enzymes from the liver and fat, causing increased estrogen levels and thus an increased morbidity of EC.

Although we currently understand some aspects of the pathogenesis and etiology of type I EC, there are still many unresolved issues regarding the whole EC disease and reproductive health system. For example, for a long time, researchers have consistently focused on the roles of estrogen and progestational hormone in the pathogenesis of type I
EC [3], but have overlooked the possible influence of other hormones. Therefore, it is very important to clarify the high-risk internal secretions resulting in type I EC and even potential blood diagnostic indicators. A recent study has reported high androgen levels as a risk factor of EC [14]. In fact, the prevalence of EC is higher in postmenopausal women than in women during reproductive years. However, we cannot ignore the irregular non-ovulatory menstrual cycles in perimenopausal periods also expected to increase the risk of EC. But it is difficult to define accurately whether women are experiencing perimenopause. Therefore, in the present study, we examined the roles of sex hormones and insulin in total, premenppausal, and postmenppausal women. We determined the correlations of androgen and insulin levels in serum with type I EC risk, and the combined effect of androgen and insulin on type I EC. These findings contribute to the diagnosis and pathogenesis of type I EC.

\section{Materials and Methods}

\section{Patient samples and control subjects}

A total of 510 patients with type I EC and 510 control patients at Tianjin Medical University General Hospital were included in the study and were recruited from August 19th 2003 to November $4^{\text {th }}$, 2015. Inclusion criteria were the patients with the first diagnosis of histologically confirmed type I EC and without other malignancies, none of whom received hormone therapy, radiotherapy, or chemotherapy prior to surgery. Control subjects were selected among women who presented for routine examination in the general physical examination center. None had a history of cancer, and they were age-, time-, and nationality-matched to the patients. The exclusion criteria for all the subjects were as follows: thyroid diseases, hepatic dysfunction, renal inadequacy, non-classical congenital adrenal hyperplasia $(\mathrm{NCAH})$, androgen-secreting tumors or use of medicines in the past 6 months that affect reproductive or metabolic functions. No history of oophorectomy.

Clinicopathological information was blindly and independently examined by two pathologists. Height, weight, waistline, abdominal perimeter, and hipline were measured immediately after serum collection for all patients and healthy subjects. Information on nulliparous, age at menopause, irregular menstruation, diabetes, hypertension, and family history of cancer was also collected from each subject. Using these parameter estimates, the waist-to-hip ratio [WHR, waistline $(\mathrm{m}) /$ hipline $(\mathrm{m})$ ], body mass index [BMI, weight $(\mathrm{kg}) /$ height $\left.^{2}\left(\mathrm{~m}^{2}\right)\right]$, and 
homeostasis model assessment-insulin resistance [HOMA-IR; plasma glucose $(\mathrm{mmol} / \mathrm{L}) \times$ serum insulin $(\mathrm{mIU} / \mathrm{L})] / 22.5]$ were calculated.

\section{Serum collection}

One 5-mL blood specimen was collected early in the morning after 6 hours of fasting and prior to surgery (for patients) or on the day of regular examination (for healthy subjects). The samples were centrifuged $(1000 \times g, 10 \mathrm{~min})$, and the serum was separated and stored at $-80^{\circ} \mathrm{C}$. Sex hormones (including total testosterone, androstenedione, estradiol and estrone) and insulin were examined according to the manufacturers' (see Serum analysis section for details) instructions.

\section{Serum analysis}

The Estrone Radioimmunoassay Kit (Diagnostic Systems Laboratories, Inc., Webster, TX, USA) was used to quantify serum levels of estrone. Chemiluminescence reagents used to quantify serum levels of insulin, estradiol, total testosterone and sex hormone-binding globulin (SHBG) were obtained from Siemens Medical Solutions (Malvern, PA, USA). The Active Androstenedione Radio Immunity Assay kit (Beckman Coulter, Inc., Miami, FL, USA) was used for the androstenedione analysis. The electrochemiluminescence method (Roche Diagnostics $\mathrm{GmbH}$, Mannheim, Germany) was used to assess the levels of C-peptide. The free androgen index (FAI) was calculated as:

FAI $=[$ total testosterone $(\mathrm{nmol} / \mathrm{L}) /$ SHBG $(\mathrm{nmol} / \mathrm{L})] \times 100$

where $1.00 \mathrm{nmol} / \mathrm{L}$ total testosterone $=28.84$ $\mathrm{ng} / \mathrm{dL}$ total testosterone. Experimental results are expressed as means \pm SD of three independent experiments for each sample.

\section{Statistical analysis}

Conditional logistic regression was used to analyze the risk factors for EC. Multiple comparisons were analyzed using Wilcoxon sign-rank tests or one-way ANOVA. A subsequent least significant difference (LSD) test was used if the variances were equal, and Tamhane's T2 test was used if the variances were unequal. The association between androgen levels and EC risk, and the association between androgen levels and clinicopathological characteristics were measured by unconditional logistic regression. Odds ratios (ORs) and 95\% confidence intervals (CIs) were estimated for the associations between total testosterone, androstenedione, insulin, other potential risk factors, and EC. All statistical tests were two-sided. Analyses were performed using the SPSS 18.0 package.

\section{Results}

\section{Basic characteristics of type I EC and control subjects}

Here, only the type I EC was under investigation. The basic characteristics of the total, premenopausal, and postmenopausal subjects (EC cases and healthy controls), including marker concentrations in serum, are displayed in Table $\mathbf{1}$. Compared with the control subjects, the weight, waist circumference, abdominal circumference, hip circumference, BMI, WHR, and HOMA-IR were significantly higher in the total, premenopausal, and postmenopausal patients with EC than in controls $(P$ $<$ 0.05). Additionally, diabetes, hypertension, irregular menstruation, and family history of cancer were also more prevalent among the total, premenopausal, and postmenopausal patients with EC than in the control subjects $(P<0.05)$. The selfreported nulliparous history was more prevalent among the total and postmenopausal patients with EC than in the control subjects $(P<0.05)$. Conversely, there were no significant differences in age, height, and self-reported age at menopause between the total and postmenopausal groups $(P>0.05)$. Serum insulin, total testosterone, androstenedione, C-peptide and FAI levels were notably higher $(P<0.05)$ whereas SHBG level was significantly lower $(P<0.001)$ in the total, premenopausal, and postmenopausal EC subjects compared to the controls. Compared with the control subjects, the total and postmenopausal EC patients had significantly higher serum concentration of estrone $(P<0.001)$, but did not differ significantly in serum concentration of estradiol $(P>0.05)$. On the contrary, serum estradiol concentration was notably higher $(P<0.05)$ whereas estrone concentration was not notably higher $(P>0.05)$ in the premenopausal EC cases compared to the controls.

Additionally, of the 510 EC patients, 387 (75.88\%) patients presented with International Federation of Gynecology and Obstetrics (FIGO) stage I, 32 (6.27\%) cases with stage II, 73 (14.31\%) ones with stage III, and $18(3.54 \%)$ patients with stage IV disease. In terms of the histopathologic grade, there were $242(47.45 \%)$ patients with G1, $212(41.57 \%)$ ones with G2, and 56 $(10.98 \%)$ cases with G3. There were 393 (77.06\%) patients had $<1 / 2$ myometrial invasion and 117 $(22.94 \%)$ cases had $\geq 1 / 2$ myometrial invasion.

\section{Serum androgen and insulin concentrations are independent risk factors for type I EC}

Using a univariate logistic model, we detected positive associations between type I EC risk and serum C-peptide, estrone, insulin, and androgen (including testosterone and androstenedione) levels, 
BMI, WHR, family history of cancer, nulliparous, irregular menstruation, diabetes, and hypertension $(P$ $<0.001$; Table 2). Per multivariate logistic modeling, the testosterone concentration (OR, 1.791; 95\% CI, 1.259-2.548; $P=0.001$ ) retained a positive association with EC after adjustment for BMI, WHR, family history of cancer, high serum insulin and estrone levels, suggesting that the testosterone level represented an independent risk factor for type I EC. Furthermore, multivariate logistic regression analyses also revealed that C-peptide level, nulliparous, irregular menstruation, diabetes, and hypertension remained positively correlated with type I EC (Table 2).

Table 1. Basic characteristics of the total, premenopausal and postmenopausal women with type I EC and healthy subjects

\begin{tabular}{|c|c|c|c|c|c|c|c|c|c|}
\hline & \multicolumn{2}{|c|}{ Total women $(n=1020)$} & \multirow[t]{2}{*}{$P$ value } & \multicolumn{2}{|c|}{ Premenopausal women $(\mathrm{n}=328)$} & \multirow[t]{2}{*}{$P$ value } & \multicolumn{2}{|c|}{ Postmenopausal women $(n=692)$} & \multirow[t]{2}{*}{$P$ value } \\
\hline & Cases $(n=510)$ & Controls $(n=510)$ & & Cases $(n=157)$ & Controls $(n=171)$ & & Cases $(n=353)$ & Controls $(n=339)$ & \\
\hline Age & $57.92 \pm 9.63$ & $57.04 \pm 10.41$ & 0.157 & $48.97 \pm 7.70$ & $46.81 \pm 4.26$ & 0.002 & $61.91 \pm 7.49$ & $62.19 \pm 8.63$ & 0.643 \\
\hline Height $(\mathrm{cm})$ & $159.69 \pm 5.52$ & $159.86 \pm 5.23$ & 0.620 & $160.06 \pm 5.47$ & $161.30 \pm 4.83$ & 0.031 & $159.53 \pm 5.55$ & $159.13 \pm 5.28$ & 0.339 \\
\hline Weight (Kg) & $69.47 \pm 13.50$ & $62.98 \pm 9.57$ & $<0.001$ & $72.25 \pm 15.95$ & $63.13 \pm 9.52$ & $<0.001$ & $68.25 \pm 12.08$ & $62.91 \pm 9.61$ & $<0.001$ \\
\hline $\mathrm{WC}(\mathrm{cm})$ & $91.36 \pm 10.87$ & $85.90 \pm 10.88$ & $<0.001$ & $92.18 \pm 12.34$ & $82.47 \pm 9.55$ & $<0.001$ & $91.00 \pm 10.15$ & $87.633 \pm 11.11$ & $<0.001$ \\
\hline $\mathrm{AC}(\mathrm{cm})$ & $97.52 \pm 11.76$ & $88.99 \pm 10.73$ & $<0.001$ & $98.14 \pm 13.79$ & $85.47 \pm 9.92$ & $<0.001$ & $97.25 \pm 10.74$ & $90.77 \pm 10.70$ & $<0.001$ \\
\hline $\mathrm{HC}(\mathrm{cm})$ & $99.80 \pm 11.35$ & $97.72 \pm 7.48$ & 0.001 & $100.56 \pm 13.69$ & $97.49 \pm 7.24$ & 0.013 & $99.74 \pm 8.65$ & $97.83 \pm 7.61$ & 0.002 \\
\hline $\operatorname{BMI}\left(\mathrm{Kg} / \mathrm{m}^{2}\right)$ & $27.15 \pm 4.99$ & $24.65 \pm 3.62$ & $<0.001$ & $27.98 \pm 6.19$ & $24.27 \pm 3.52$ & $<0.001$ & $26.78 \pm 4.32$ & $24.85 \pm 3.66$ & $<0.001$ \\
\hline WHR & $0.93 \pm 0.37$ & $0.88 \pm 0.09$ & 0.004 & $0.96 \pm 0.66$ & $0.85 \pm 0.07$ & 0.022 & $0.91 \pm 0.07$ & $0.90 \pm 0.09$ & 0.006 \\
\hline HOMA-IR & $2.83(1.81-4.09)$ & $1.76(1.18-2.63)$ & $<0.001$ & $3.51 \pm 3.93$ & $1.95 \pm 1.20$ & $<0.001$ & $3.32 \pm 2.47$ & $2.26 \pm 1.68$ & $<0.001$ \\
\hline Age at menopause & $50.20 \pm 5.03$ & $50.32 \pm 3.35$ & 0.719 & - & - & - & $50.20 \pm 5.03$ & $50.32 \pm 3.35$ & 0.719 \\
\hline Nulliparous (\%) & 9.02 & 3.73 & 0.001 & 12.7 & 7.0 & 0.081 & 7.4 & 2.1 & 0.001 \\
\hline $\begin{array}{l}\text { Irregular menstruation } \\
(\%)\end{array}$ & 20.20 & 2.70 & $<0.001$ & 49.7 & 7.8 & $<0.001$ & 7.1 & 3.0 & 0.045 \\
\hline Diabetes (\%) & 28.04 & 6.27 & $<0.001$ & 33.8 & 1.8 & $<0.001$ & 25.5 & 8.6 & $<0.001$ \\
\hline Hypertension (\%) & 47.45 & 22.94 & $<0.001$ & 38.2 & 11.1 & $<0.001$ & 51.6 & 28.9 & $<0.001$ \\
\hline $\begin{array}{l}\text { Family history of cancer } \\
(\%)\end{array}$ & 29.41 & 16.27 & $<0.001$ & 27.4 & 15.2 & 0.007 & 30.3 & 16.8 & $<0.001$ \\
\hline Estrone $(\mathrm{pg} / \mathrm{mL})$ & $46.76(33.08-65.04)$ & $38.54(28.46-56.76)$ & $<0.001$ & $58.58(43.03-79.09)$ & $58.480(39.29-84.18)$ & 0.816 & $43.30(30.33-57.43)$ & $34.52(25.59-43.66)$ & $<0.001$ \\
\hline Estradiol (pg/mL) & $20.97(12.13-36.09)$ & $21.01(14.62-34.73)$ & 0.589 & 43.17(19.51-73.89) & $63.29(22.26-104.82)$ & 0.032 & $18.05(11.04-27.78)$ & $18.60(12.00-23.77)$ & 0.241 \\
\hline Insulin $(\mu \mathrm{IU} / \mathrm{mL})$ & $10.37(7.26-14.99)$ & $7.53(5.21-10.68)$ & $<0.001$ & $10.74(7.58-15.12)$ & $7.53(5.22-10.24)$ & $<0.001$ & $10.13(7.12-15.00)$ & $7.53(5.18-10.80)$ & $<0.001$ \\
\hline Testosterone (ng/dL) & $43.20(33.00-59.00)$ & $36.96(25.00-45.38)$ & $<0.001$ & $43.00(29.87-59.46)$ & $35.70(21.73-46.00)$ & $<0.001$ & $43.40(31.73-58.72)$ & $38.00(26.00-51.43)$ & $<0.001$ \\
\hline $\begin{array}{l}\text { Androstenedione } \\
(\mathrm{ng} / \mathrm{mL})\end{array}$ & $1.68(1.16-2.40)$ & $1.33(0.92-31.94)$ & $<0.001$ & $1.86(1.30-2.53)$ & $1.59(1.13-2.23)$ & 0.027 & $1.63(1.12-2.34)$ & $1.18(0.86-1.74)$ & $<0.001$ \\
\hline SHBG (nmol/L) & $35.80(26.00-48.93)$ & $48.80(34.95-66.60)$ & $<0.001$ & $34.20(24.50-48.00)$ & $51.00(33.80-69.10)$ & $<0.001$ & $37.00(27.00-49.90)$ & $47.80(36.00-66.10)$ & $<0.001$ \\
\hline FAI $(\%)$ & $4.16(2.50-6.96)$ & $2.53(1.50-4.20)$ & $<0.001$ & $4.25(2.45-7.62)$ & $2.40(1.44-3.76)$ & $<0.001$ & $4.09(2.52-6.78)$ & $2.65(1.57-4.30)$ & $<0.001$ \\
\hline C-peptide (ng/mL) & $1.30(0.85-2.03)$ & $0.95(0.59-1.39)$ & $<0.001$ & $1.42(0.88-2.20)$ & $0.88(0.54-1.23)$ & $<0.001$ & $1.27(0.84-1.90)$ & $1.02(0.61-1.50)$ & $<0.001$ \\
\hline
\end{tabular}

WC, waist circumference; AC, abdominal circumference; HC, hip circumference; BMI, body mass index; WHR, waist-to-hip ratio; HOMA-IR, homeostasis model assessment-insulin resistance; FAI, free androgen index.

Continuous variables are shown as means ( \pm standard deviation) whereas categorical variables are shown as their positive percentages;

Medians (25-75\%) of serum steroid sex hormones, insulin, C-peptide, and SHBG (sex hormone-binding globulin) concentrations in patients with endometrial cancer (EC) and control subjects;

Bold text denotes statistical significance, $P<0.05$.

Table 2. Odds ratio for type I EC risk using logistic regression

\begin{tabular}{|c|c|c|c|c|c|c|}
\hline & \multicolumn{3}{|c|}{ Univariate logistic regression } & \multicolumn{3}{|c|}{ Multivariate logistic regression } \\
\hline & $\overline{\mathrm{OR}}$ & $95 \% \mathrm{CI}$ & $P$ value & $\mathrm{OR}^{\mathrm{a}}$ & $95 \% \mathrm{CI}$ & $P$ value \\
\hline Testosterone (ng/dL) & 1.656 & $1.293-2.121$ & $<0.001$ & 1.791 & $1.259-2.548$ & 0.001 \\
\hline Androstenedione (ng/mL) & 2.057 & $1.603-2.640$ & $<0.001$ & 0.959 & $0.658-1.397$ & 0.826 \\
\hline SHBG (nmol/L) & 0.335 & $0.260-0.432$ & $<0.001$ & 0.475 & $0.331-0.683$ & $<0.001$ \\
\hline C-peptide (ng/mL) & 2.504 & $1.946-3.222$ & $<0.001$ & 4.004 & $2.686-5.969$ & $<0.001$ \\
\hline Insulin $(\mu \mathrm{IU} / \mathrm{mL})$ & 2.934 & $2.275-3.783$ & $<0.001$ & 0.845 & $0.564-1.265$ & 0.414 \\
\hline Estrone $(\mathrm{pg} / \mathrm{mL})$ & 2.041 & $1.590-2.619$ & $<0.001$ & 1.446 & $0.997-2.097$ & 0.052 \\
\hline Estradiol (pg/mL) & 1.000 & $0.782-1.278$ & 1.000 & & & \\
\hline $\mathrm{BMI}(\mathrm{Kg} / \mathrm{m} 2)$ & 2.411 & $1.854-3.136$ & $<0.001$ & 0.983 & $0.663-1.457$ & 0.932 \\
\hline WHR & 3.894 & $2.871-5.282$ & $<0.001$ & 1.124 & $0.726-1.739$ & 0.600 \\
\hline Diabetes (\%) & 5.820 & $3.875-8.741$ & $<0.001$ & 4.153 & $2.358-7.316$ & $<0.001$ \\
\hline Hypertension (\%) & 3.033 & $2.316-3.973$ & $<0.001$ & 2.155 & $1.466-3.166$ & $<0.001$ \\
\hline Nulliparous (\%) & 2.562 & $1.479-4.438$ & 0.001 & 5.990 & $2.160-16.609$ & 0.001 \\
\hline Irregular menstruation (\%) & 5.244 & $2.930-9.315$ & $<0.001$ & 3.301 & $1.753-6.218$ & $<0.001$ \\
\hline Family history of cancer (\%) & 2.144 & $1.584-2.901$ & $<0.001$ & 1.443 & $0.976-2.135$ & 0.066 \\
\hline
\end{tabular}

BMI, body mass index; WHR, waist-to-hip ratio; $\mathrm{OR}$, odds ratio; $\mathrm{CI}$, confidence interval.

a: Adjusted for insulin, estrone, BMI, WHR, and family history of cancer.

Bold text denotes statistical significance, $P<0.05$. 
Table 3. The relationship between testosterone, androstenedione, insulin, FAI and type I EC risk after stratification for BMI, WHR, diabetes, hypertension using logistic regression model in total women

\begin{tabular}{|c|c|c|c|c|c|c|c|c|c|c|c|c|}
\hline & \multicolumn{3}{|c|}{ Testosterone } & \multicolumn{3}{|c|}{ Androstenedione } & \multicolumn{3}{|c|}{ Insulin } & \multicolumn{3}{|l|}{ FAI } \\
\hline & $\overline{\mathrm{OR}}$ & $95 \% \mathrm{CI}$ & $P$ value & OR & $95 \% \mathrm{CI}$ & $P$ value & OR & $95 \% \mathrm{CI}$ & $P$ value & OR & $95 \% \mathrm{CI}$ & $P$ value \\
\hline \multicolumn{13}{|l|}{ BMI } \\
\hline$<24$ & 1.202 & $0.787-1.837$ & 0.394 & 1.626 & $1.062-2.489$ & 0.025 & 2.748 & $1.706-4.427$ & $<0.001$ & 2.855 & $1.617-5.038$ & $<0.001$ \\
\hline$\geq 24$ & 1.885 & $1.375-2.585$ & $<0.001$ & 2.363 & $1.717-3.252$ & $<0.001$ & 2.304 & $1.660-3.196$ & $<0.001$ & 3.495 & $2.423-5.040$ & $<0.001$ \\
\hline \multicolumn{13}{|l|}{ WHR } \\
\hline$<0.85$ & 0.694 & $0.402-1.200$ & 0.191 & 1.699 & $0.991-2.914$ & 0.054 & 2.921 & $1.621-5.265$ & $<0.001$ & 2.000 & $0.911-4.388$ & 0.084 \\
\hline$\geq 0.85$ & 2.058 & $1.530-2.766$ & $<0.001$ & 2.097 & $1.559-2.820$ & $<0.001$ & 2.129 & $1.578-2.872$ & $<0.001$ & 3.298 & $2.341-4.645$ & $<0.001$ \\
\hline \multicolumn{13}{|c|}{ Diabetes } \\
\hline No & 1.722 & $1.308-2.266$ & $<0.001$ & 1.908 & $1.448-2.513$ & $<0.001$ & 2.581 & $1.951-3.414$ & $<0.001$ & 3.220 & $2.315-4.479$ & $<0.001$ \\
\hline Yes & 1.500 & $0.693-3.246$ & 0.303 & 2.830 & $1.282-6.249$ & 0.01 & 1.851 & $0.823-4.165$ & 0.137 & 5.035 & $1.836-13.811$ & 0.002 \\
\hline \multicolumn{13}{|c|}{ Hypertension } \\
\hline No & 1.696 & $1.240-2.320$ & 0.001 & 1.570 & $1.149-2.146$ & 0.005 & 2.918 & $2.112-4.032$ & $<0.001$ & 3.959 & $2.718-5.766$ & $<0.001$ \\
\hline Yes & 2.751 & $1.745-4.335$ & $<0.001$ & 1.686 & $1.081-2.630$ & 0.021 & 1.683 & $1.059-2.675$ & 0.028 & 3.006 & $1.755-5.147$ & $<0.001$ \\
\hline
\end{tabular}

The cut-off points for serum testosterone, androstenedione and insulin concentrations were $40.10 \mathrm{ng} / \mathrm{dL}, 1.47 \mathrm{ng} / \mathrm{mL}$ and $8.82 \mathrm{mIU} / \mathrm{mL}$, respectively.

$\mathrm{FAI} \geq 5 \%$ of serum levels were more than the reference interval limitation.

OR, odds ratio; $\mathrm{CI}$, confidence interval.

Bold text denotes statistical significance, $P<0.05$.

\section{Relationship between testosterone, androstenedione, insulin and FAI levels with type I EC risk after stratification for BMI, WHR, diabetes, and hypertension}

After EC risk factors, including BMI, WHR, diabetes, and hypertension, were stratified, the relationships between type I EC risk and total testosterone, androstenedione, insulin and FAI levels were analyzed in total women (Table 3). Testosterone was associated with increased EC risk upon stratification for BMI over $24 \mathrm{~kg} / \mathrm{m}^{2}$ (OR, 1.885; 95\% CI, 1.375-2.585; $P<0.001)$, WHR over 0.85 (OR, 2.058; 95\% CI, 1.530-2.766; $P<0.001)$, and for women without diabetes (OR, 1.722; 95\% CI, 1.308-2.266; $P<$ 0.001 ), whereas there were no significant associations in subjects with BMI less than $24 \mathrm{~kg} / \mathrm{m}^{2}$, WHR less than 0.85 , and in women with diabetes $(P>0.05$, Table 3). Insulin was found to increase EC risk in all stratified data $(P<0.05)$ except, in women with diabetes $(P=0.137$, Table 3$)$. Similarly, androstenedione and FAI were associated with increased EC risk in all of the risk factor stratifications $(P<0.05)$, except in women with WHR less than $0.85(P=0.054$, Table 3).

\section{Higher serum androgen and insulin levels increase the risk for type I EC}

To investigate whether insulin and androgen synergistically enhance patient risk for type I EC, we analyzed the odds ratios of total testosterone, androstenedione, FAI, and insulin for EC using a logistic regression model, according to stratified data. First, the total testosterone, androstenedione, and insulin concentrations were stratified into median values according to their distribution among EC patients and controls. The cut-off points for serum total testosterone, androstenedione, and insulin concentrations were $40.10,39.02$, and $41.00 \mathrm{ng} / \mathrm{dL}$,
1.47, 1.75, and $1.39 \mathrm{ng} / \mathrm{mL}$, and 8.82, 8.74, and 8.90 $\mathrm{mIU} / \mathrm{mL}$ in total, premenopausal, and postmenopausal women, respectively. The FAI levels were divided into less than $5 \%$ and more than $5 \%$ among EC patients and controls.

Compared with the lower stratification groups, ORs for the higher stratifications in total, premenopausal, and postmenopausal women for total testosterone were 1.656 (95\% CI, 1.293-2.121; $P<$ $0.001), 1.851$ (95\% CI, 1.194-2.870; $P=0.006$ ), and 1.520 (95\% CI, 1.126-2.051; $P=0.006$ ), respectively (Table 4). However, similar comparisons for androstenedione were not significant $(P=0.151$; Table 4$)$ in the premenopausal group. Additionally, an increased insulin level was positively correlated with EC risk in total (OR, 2.934; 95\% CI, 2.275-3.783; $P<0.001$ ), premenopausal (OR, 4.280, 95\% CI, 2.695-6.796; $P<$ 0.001 ), and postmenopausal women (OR, 2.414; 95\% CI, 1.779-3.277; $P<0.001$ ), respectively (Table 4).

To investigate whether high serum androgen and insulin levels were synergistic EC risk factors, we analyzed the ORs for testosterone, androstenedione, FAI, and insulin for EC using logistic regression models with stratified data. We found that compared with both higher testosterone and insulin, ORs for higher testosterone with lower insulin and lower testosterone with higher insulin were decreased in a stratified analysis of total, premenopausal, and postmenopausal women (Table 4). Coordinately, compared with both higher androstenedione and insulin, ORs for higher androstenedione with lower insulin and lower androstenedione with higher insulin were decreased in a stratification analysis of total and postmenopausal women (Table 4). Finally, compared to both higher FAI and insulin, ORs for higher FAI with lower insulin and lower FAI with higher insulin were decreased in all three groups (Table 4). 


\section{Discussion}

$\mathrm{EC}$ is the most common gynecological malignancy. About $14 \%$ of all cases are diagnosed in premenopausal women (a minority of which may have not yet completed childbearing), whereas the vast majority of EC occurs after menopause. Type I is the most commonly diagnosed form (about $80 \%$ of the cases) and is related to a prolonged estrogen exposure, as encountered in case of obesity, nulliparity, early menarche, late menopause (> 55 years), and polycystic ovarian syndrome (PCOS). However, in contrast to studies regarding estrogens, the possible impact of androgen and insulin actions on type I EC has largely remained unknown. Therefore, we discuss the effects of androgen and insulin in type I EC in this part.

\section{Occurrence of type I endometrial carcinoma is} regulated by steroid hormones

Type I EC risk is thought to be associated with two major regulatory systems, i.e., sex hormonal mechanisms and the growth factor system. Largescale case studies have supported these associations. More specifically, insulin resistance, steroid hormones, and inflammation are related to a high type I EC occurrence [15]. The normal endometrium is regulated periodically by various hormonal signals from the ovaries (mainly estrogen, progesterone, and androgen), which act via their own hormone receptors to transmit signals [3]. Currently, the longterm stimulation of estrogen without the antagonist progesterone is considered the main causal factor for EC. However, the theory of the progesterone-estrogen antagonism cannot account for all etiologies of type I EC.

Table 4. Serum higher androgen and insulin concentrations increase the risk for type I EC according to a logistic regression model

\begin{tabular}{|c|c|c|c|c|c|c|c|c|c|c|c|c|}
\hline & \multicolumn{4}{|c|}{ Total women $(n=1020)$} & \multicolumn{4}{|c|}{ Premenopausal women $(n=328)$} & \multicolumn{4}{|c|}{ Postmenopausal women $(n=692)$} \\
\hline & $\begin{array}{l}\text { Case } \\
n=510(\%)\end{array}$ & $\begin{array}{l}\text { Control } \\
\mathrm{n}=510(\%)\end{array}$ & OR $(95 \%$ CI $)$ & $P$ value & $\begin{array}{l}\text { Case } \\
\mathrm{n}=157(\%)\end{array}$ & $\begin{array}{l}\text { Control } \\
n=171(\%)\end{array}$ & OR $(95 \% \mathrm{CI})$ & $P$ value & $\begin{array}{l}\text { Case } \\
\mathrm{n}=353(\%)\end{array}$ & $\begin{array}{l}\text { Control } \\
n=339(\%)\end{array}$ & OR $(95 \% \mathrm{CI})$ & $\begin{array}{l}P \\
\text { value }\end{array}$ \\
\hline \multicolumn{13}{|c|}{ Testosterone } \\
\hline$<50 \%$ & $223(43.7)$ & $287(56.3)$ & & Ref & $66(42.0)$ & $98(57.3)$ & Ref & Ref & $160(45.3)$ & $189(55.8)$ & Ref & Ref \\
\hline$\geq 50 \%$ & $287(56.3)$ & $223(43.7)$ & $1.656(1.293-2.121)$ & $<0.001$ & $91(58.0)$ & $73(42.7)$ & $1.851(1.194-2.870)$ & 0.006 & $193(54.7)$ & $150(44.2)$ & $1.520(1.126-2.051)$ & 0.006 \\
\hline \multicolumn{13}{|c|}{ Androstenedione } \\
\hline$<50 \%$ & $210(41.2)$ & $301(59.0)$ & Ref & Ref & $72(45.9)$ & $92(53.8)$ & Ref & Ref & $135(38.2)$ & $214(63.1)$ & Ref & Ref \\
\hline$\geq 50 \%$ & $300(58.2)$ & $209(41.0)$ & $2.057(1.603-2.640)$ & $<0.001$ & $85(54.1)$ & $79(46.2)$ & $1.375(0.890-2.123)$ & 0.151 & $218(61.8)$ & $125(36.9)$ & $2.765(2.032-3.761)$ & $<0.001$ \\
\hline \multicolumn{13}{|c|}{ Insulin } \\
\hline$<50 \%$ & $188(36.9)$ & $322(63.1)$ & Ref & Ref & $50(31.8)$ & $114(66.7)$ & Ref & Ref & $139(39.4)$ & $207(61.1)$ & Ref & Ref \\
\hline$\geq 50 \%$ & $322(63.1)$ & $188(36.9)$ & $2.934(2.275-3.783)$ & $<0.001$ & $107(68.2)$ & $57(33.3)$ & $4.280(2.695-6.796)$ & $<0.001$ & $214(60.6)$ & $132(38.9)$ & 2.414 (1.779-3.277) & $<0.001$ \\
\hline \multicolumn{13}{|c|}{ Testosterone+Insulin } \\
\hline \multicolumn{13}{|c|}{ Testosterone $<50 \%$} \\
\hline \multicolumn{13}{|c|}{ Insulin } \\
\hline$<50 \%$ & $101(19.8)$ & $179(35.1)$ & Ref & Ref & $22(14.0)$ & $63(36.8)$ & Ref & Ref & $78(22.1)$ & $113(33.3)$ & Ref & Ref \\
\hline$\geq 50 \%$ & $122(23.9)$ & $108(21.2)$ & 2.002 (1.403-2.857) & $<0.001$ & $44(28.0)$ & $35(20.5)$ & $3.600(1.865-6.950)$ & $<0.001$ & $82(23.2)$ & $76(22.4)$ & $1.563(1.022-2.391)$ & 0.039 \\
\hline \multicolumn{13}{|c|}{ Testosterone $\geq 50 \%$} \\
\hline \multicolumn{13}{|c|}{ Insulin } \\
\hline$<50 \%$ & 87 (17.1) & $143(28.0)$ & $1.078(0.751-1.547)$ & 0.683 & $28(17.8)$ & $51(29.8)$ & $1.572(0.805-3.071)$ & 0.185 & $61(17.3)$ & $94(27.7)$ & $0.94(0.610-1.449)$ & 0.78 \\
\hline$\geq 50 \%$ & $200(39.2)$ & $80(15.7)$ & 4.431 (3.104-6.325) & $<0.001$ & $63(40.1)$ & $22(12.9)$ & $8.200(4.128-16.291)$ & $<0.001$ & $132(37.4)$ & $56(16.5)$ & $3.415(2.232-5.225)$ & $<0.001$ \\
\hline \multicolumn{13}{|c|}{ Androstenedione+Insulin } \\
\hline \multicolumn{13}{|c|}{ Androstenedione $<50 \%$} \\
\hline \multicolumn{13}{|c|}{ Insulin } \\
\hline$<50 \%$ & $92(18.0)$ & $195(38.2)$ & Ref & Ref & $25(15.9)$ & $67(39.2)$ & Ref & Ref & $63(17.8)$ & $137(40.4)$ & Ref & Ref \\
\hline$\geq 50 \%$ & $118(23.1)$ & $106(20.8)$ & $2.360(1.645-3.385)$ & $<0.001$ & $47(29.9)$ & $25(14.6)$ & $5.038(2.583-9.828)$ & $<0.001$ & $72(20.4)$ & $77(22.7)$ & $2.033(1.312-3.152)$ & 0.002 \\
\hline \multicolumn{13}{|c|}{ Androstenedione $\geq 50 \%$} \\
\hline \multicolumn{13}{|l|}{ Insulin } \\
\hline$<50 \%$ & $96(18.8)$ & $127(24.9)$ & $1.602(1.115-2.303)$ & 0.011 & $25(15.9)$ & $47(27.5)$ & $1.426(0.731-2.781)$ & 0.298 & $76(21.5)$ & $70(20.6)$ & 2.361 (1.519-3.669) & $<0.001$ \\
\hline$\geq 50 \%$ & $204(40.0)$ & $82(16.1)$ & $5.273(3.692-7.532)$ & $<0.001$ & $60(38.2)$ & $32(18.7)$ & $5.025(2.680-9.421)$ & $<0.001$ & $142(40.2)$ & $55(16.2)$ & $5.614(3.648-8.641)$ & 0.001 \\
\hline \multicolumn{13}{|c|}{ FAI+Insulin } \\
\hline \multicolumn{13}{|c|}{$F A I<5 \%$} \\
\hline \multicolumn{13}{|c|}{ Insulin } \\
\hline$<50 \%$ & $137(26.9)$ & $286(56.1)$ & Ref & Ref & $36(22.9)$ & $106(62.0)$ & Ref & Ref & $103(29.2)$ & $179(52.8)$ & Ref & Ref \\
\hline$\geq 50 \%$ & $172(33.7)$ & $148(29.0)$ & $2.426(1.798-3.274)$ & $<0.001$ & $54(34.4)$ & $48(28.1)$ & $3.312(1.926-5.698)$ & $<0.001$ & $116(32.8)$ & $101(29.8)$ & $1.996(1.392-2.862)$ & $<0.001$ \\
\hline \multicolumn{13}{|c|}{$F A I \geq 5 \%$} \\
\hline \multicolumn{13}{|c|}{ Insulin } \\
\hline$<50 \%$ & $51(10.0)$ & $36(7.1)$ & 2.957 (1.843-4.745) & $<0.001$ & $14(8.9)$ & $8(4.7)$ & $5.153(1.998-13.289)$ & 0.001 & $36(10.2)$ & $28(8.3)$ & $2.234(1.289-3.873)$ & 0.004 \\
\hline$\geq 50 \%$ & $150(29.4)$ & $40(7.8)$ & $7.828(5.227-11.724)$ & $<0.001$ & $53(33.8)$ & $9(5.3)$ & $17.340(7.780-38.644)$ & $<0.001$ & $98(27.8)$ & $31(9.1)$ & $5.494(3.430-8.799)$ & $<0.001$ \\
\hline $\begin{array}{l}\text { The c } \\
\text { The c } \\
\text { The c } \\
\text { FAI } \geq \\
\text { OR, o } \\
\text { Bold }\end{array}$ & $\begin{array}{l}\text { off point } \\
\text { off point } \\
\text { off point } \\
\text { of serun } \\
\text { s ratio; } C\end{array}$ & $\begin{array}{l}\text { serum a } \\
\text { serum te } \\
\text { serum ir } \\
\text { els were } \\
\text { infidence }\end{array}$ & $\begin{array}{l}\text { ostenedione conce } \\
\text { sterone concentrat } \\
\text { in concentrations } \\
\text { re than the referen } \\
\text { erval; }\end{array}$ & $\begin{array}{l}\text { tions } \\
\text { wer }\end{array}$ & $\begin{array}{l}\text { e } 1.47,1.7 \\
10,39.02 \\
4 \text { and } 8.90 \\
\text { nitation; }\end{array}$ & $\begin{array}{l}\text { nd } 1.39 \mathrm{r} \\
41.00 \mathrm{ng} \\
\mathrm{IU} / \mathrm{mL} \mathrm{i}\end{array}$ & otal, premenopaus & d po & nopa & $\begin{array}{l}\text { usal wom } \\
\text { omen, re }\end{array}$ & $\begin{array}{l}\text {, respectively; } \\
\text { respectively; } \\
\text { tively; }\end{array}$ & \\
\hline
\end{tabular}


In recent years, high androgen has been considered a new type I EC risk factor in women [16]. As we known, only the free androgen fraction is able to diffuse into the cell and exert carcinogenetic effect by binding to the androgen receptor. Therefore, we use FAI to reflect the risk of EC caused by active androgens. Our results showed increased serum androgen levels in type I EC patients (Table 1 \& Table 4), consistent with previous reports [17-19]. However, these previous studies have not clarified the type I EC risk after adjusting for the estrogen level, as androgen could be converted to estrogen by aromatase and aldo-keto reductase [20] and further affects the estrogenic pathway via ERs. Additionally, it has been shown that androgen, after reaching a high level, can be converted to estrogen via aromatase [17, 18], thereby increasing the level of estrogen and thus the risk of EC. In general, research has firmly established that the metabolism of local androgen from type I EC tumor tissues may be more involved after transformation into estrogen. We analyzed the type I EC risk of androgen with adjustment for estrogenic factors to address this limitation. To be specific, our research indicates that androgen, especially testosterone, affects the occurrence of type I EC tumors as an independent risk factor (Table 2), and not only as the precursor of estrogen but also androgenic pathways. Researchers reported that androgen receptor (AR) expression within the healthy endometrial epithelium and hyperplastic tissue, but expression in EC. Furthermore, loss of androgen receptor (AR) in EC is associated with poor survival [21]. These observations indirectly support the regulatory roles of androgen and $\mathrm{ARs}$ in the occurrence of EC.

\section{Occurrence of type I endometrial carcinoma is regulated by insulin levels}

Insulin is considered as an important component of the growth factor system and high levels of insulin increased type I EC risk in our study, in accordance with previous results for other cancers [22, 23]. Compared to androgen, the mechanism of insulin signaling in proliferative endometrial changes has been well-studied $[24,25]$. To be specific, insulin promotes EC progression directly via insulin signaling, and further activates various proliferation signals, including the PI3K/Akt and MAPK/ERK pathways [25]. On the other hand, insulin can promote cancer indirectly via affecting sex hormone levels. Insulin can promote the generation of androgen by both ovarian and adrenal gland sources, stimulate the production of aromatase in endometrial stroma, and facilitate androgen conversion to estrogen [26]. Moreover, the indirect cancer- promoting function of insulin also includes the inhibition of SHBG (which can tightly bind estradiol and testosterone) production in liver, elevating free sex hormones (both androgen and estrogen) in serum. In general, insulin can function indirectly via ERs and ER-mediated signaling.

As is common knowledge, the pathophysiological basis of metabolic syndromes, like obesity, hypertension, and diabetes, involves insulin resistance. Associations of morbidity of EC and these metabolic syndrome-related diseases (or risk factors) are well established. Generally, insulin, as a multi-functional protein hormone, not only widely regulates human metabolism, but also functions as a growth factor to stimulate the proliferation and differentiation of multiple cell types and to inhibit apoptosis. Therefore, hyperinsulinism or excess insulin can result in endometrial changes with a pro-proliferative, pro-survival phenotype and inflammatory changes akin to the effects of unopposed estrogen [27].

\section{The cooperative relationship of androgen (including testosterone and androstenedione) and insulin in type I EC}

Apart from ovaries, estrogen could also be derived from the adrenal gland and peripheral fat conversion; accordingly, high fat levels (especially metabolic syndrome-related central obesity caused by hyperinsulinemia) are correlated with high peripheral fat and increased conversion of androgen to estrogen $[17,18]$. Further, excess insulin stimulates theca cell androgen activity, elevates serum-free testosterone levels via decreased hepatic SHBG production, amplifies luteinizing hormone (LH) and IGF-Istimulated androgen production, and enhances serum IGF-I bioactivity via suppressed IGF binding protein production [28, 29]. In the current study, we analyzed androgen in type I EC patients by multivariate logistic regression, adjusting for other positive characteristics (including insulin, estrone, and obesity factors) in a univariate analysis. According to these analyses, high testosterone was an independent risk factor of high estrone and insulin levels for type I EC (Table 2). High androstenedione is also associated with an increased risk of type I EC, but is not an independent risk factor (Table 2).

Epidemiological studies have shown that an increased risk of EC is associated with increased exposure to androgen, including variation in $\mathrm{AR}$ genes $[30,31]$ and PCOS, leading to hyperandrogenism. Hyperandrogenism is correlated to a high tolerance to insulin [32-34], which can lead to insulin level increases and other metabolic syndromes. Excessive androgen has been reported to 
alter autophosphorylation of the insulin receptor in the ovary of a woman with PCOS, resulting in a much higher tolerance to insulin [35]. In addition, female rats exposed to androgen excess promote Ins1 expression via transcriptional regulation that might contribute for basal hyperinsulinemia [33]. These observations support the role of androgen in insulin tolerance; however, further studies are needed to clarify the causal basis.

On the other hand, apart from conversion into estrogen or the influence of insulin function, androgen itself normally regulates gene expression via $A R$, a positive prognostic indicator, and its loss is associated with shorter disease-free survival [21]; therefore, the androgenic pathway as a therapeutic target for EC is not clearly established and requires further investigation. Our data revealed that the risk of both androgen and insulin increasing is higher than that of only a single factor increasing (Table 4), suggesting that androgen and insulin may have a synergistic effect on the occurrence of type I EC. Increasing evidence in prostate cancer and PCOS has revealed cross-talk between androgen and insulin signaling or its downstream cell proliferation pathways [36-38].

\section{The relationship between estrogen, androgen, and insulin}

Our group has been exploring the role of sex hormones and growth factors in the development of EC. Importantly, by comparing the serum samples from patients with type $1 \mathrm{EC}$ to the samples from healthy subjects, we discovered that high estrogen and insulin levels synergistically promoted cancer progression in the patients [39]. Our clinical observations were confirmed by experiments in cell cultures and animal models [39]. The underlying mechanism for producing the synergistic effect of estrogen and insulin levels in promoting type 1 EC progression was linked to the crosstalk between the hormones mediated by their cognate receptors [40].

Interestingly, using the serum samples from our previous study, we found that high serum androgen and insulin levels might be associated with a synergistic risk in the same patients [39]. However, these results could not be directly confirmed by testing cognate hormone receptors, indicating that the underlying mechanism involves additional molecular components. Due to menstrual processes in women, the tissues producing the sex hormones differ in premenopausal and postmenopausal women. As discussed earlier, the ovary is the main producer for premenopausal estrogen, although other sites of estrogen biosynthesis are found throughout the body. These sites include the mesenchymal cells of adipose tissues and the skin, osteoblasts and perhaps chondrocytes in bones, vascular endothelial and aortic smooth muscle cells, and several sites in the brain [3]. After menopause, circulating estrogen levels decline steeply, but testosterone levels alongside free testosterone levels did not vary by age, the mesenchymal cells of adipose tissues become the main estrogen producer due to the activity of aromatase that converts androgens to estrogens [3]. Therefore, there is a correlation between estrogen and androgen levels.

Therefore, the question is whether androgens serve as a potential estrogen reservoir or if androgens interact with insulin via an unidentified signaling mechanism. Here, we hypothesize that a signaling mechanism is involved but we do not have enough evidence to support this hypothesis. Hence, the mechanism underlying the synergistic effect of androgen and insulin levels on the occurrence of type I EC should be examined in future studies.

In conclusion, our findings showed that high serum androgen levels and insulin concentrations have synergistic effects on type I EC risk, indicating that androgens and insulin could promote type I EC occurrence via different pathways. These findings provide a reference for the pathology of type I EC with respect to androgens and a basis for further studies of the precise mechanism underlying the effects of androgens.

\section{Acknowledgements}

The authors thank the Tianjin Key Laboratory of Female Reproductive Health and Eugenics for their technical assistance. This work was supported by grants from the National Natural Science Foundation of China (No. 81572568 and No. 81802617) and Tianjin Municipal Natural Science Foundation (No. 12JCQNJC06700 and No. 18JCQNJC81200).

\section{Ethics Committee Approval and Patient consent}

The study protocol was approved by the Ethics Committee of Tianjin Medical University General Hospital, and patients and healthy individuals who presented serum samples at Tianjin Medical University General Hospital all provided informed consent.

\section{Competing Interests}

The authors have declared that no competing interest exists.

\section{References}

1. Siegel RL, Miller KD, Jemal A. Cancer statistics, 2019. CA Cancer J Clin. 2019;69(1):7-34. 
2. Chen W, Zheng R, Baade PD, et al. Cancer statistics in China, 2015. CA Cancer J Clin. 2016;66(2):115-32.

3. Kamal A, Tempest N, Parkes $\mathrm{C}$, et al. Hormones and endometrial carcinogenesis. Horm Mol Biol Clin Investig. 2016;25(2):129-48.

4. Hapangama DK, Kamal AM, Bulmer JN. Estrogen receptor beta: the guardian of the endometrium. Hum Reprod Update. 2015;21(2):174-93.

5. Li Q, Kannan A, DeMayo FJ, et al. The antiproliferative action of progesterone in uterine epithelium is mediated by Hand2. Science. 2011;331(6019):912-6.

6. Mathew D, Drury JA, Valentijn AJ, et al. In silico, in vitro and in vivo analysis identifies a potential role for steroid hormone regulation of FOXD3 in endometriosis-associated genes. Hum Reprod. 2016;31(2):345-54.

7. Kurita T, Wang YZ, Donjacour AA, et al. Paracrine regulation of apoptosis by steroid hormones in the male and female reproductive system. Cell Death Differ. 2001;8(2):192-200.

8. Schindler AE. Progestogen deficiency and endometrial cancer risk. Maturitas. 2009;62(4):334-7.

9. Trabert B, Wentzensen N, Felix AS, et al. Metabolic syndrome and risk of endometrial cancer in the united states: a study in the SEER-medicare linked database. Cancer Epidemiol Biomarkers Prev. 2015;24(1):261-7.

10. Lai Y, Sun C. Association of abnormal glucose metabolism and insulin resistance in patients with atypical and typical endometrial cancer. Oncol Lett. 2018;15(2):2173-8

11. Kabat GC, Kim MY, Lane DS, et al. Serum glucose and insulin and risk of cancers of the breast, endometrium, and ovary in postmenopausal women. Eur J Cancer Prev. 2018;27(3):261-8

12. Shao R, Li X, Feng Y, et al. Direct effects of metformin in the endometrium: a hypothetical mechanism for the treatment of women with PCOS and endometrial carcinoma. J Exp Clin Cancer Res. 2014;33:41.

13. Dunaif A, Segal KR, Futterweit W, et al. Profound peripheral insulin resistance, independent of obesity, in polycystic ovary syndrome. Diabetes. 1989;38(9):1165-74

14. Gibson DA, Simitsidellis I, Collins F, et al. Evidence of androgen action in endometrial and ovarian cancers. Endocr Relat Cancer. 2014;21(4):T203-18.

15. Dossus L, Lukanova A, Rinaldi S, et al. Hormonal, metabolic, and inflammatory profiles and endometrial cancer risk within the EPIC cohort--a factor analysis. Am J Epidemiol. 2013;177(8):787-99.

16. Michels KA, Brinton LA, Wentzensen N, et al. Postmenopausal Androgen Metabolism and Endometrial Cancer Risk in the Women's Health Initiative Observational Study. JNCI Cancer Spectr. 2019;3(3):z29.

17. Bulun SE, Lin Z, Imir G, et al. Regulation of aromatase expression in estrogen-responsive breast and uterine disease: from bench to treatment. Pharmacol Rev. 2005;57(3):359-83.

18. Gao C, Wang Y, Tian W, et al. The therapeutic significance of aromatase inhibitors in endometrial carcinoma. Gynecol Oncol. 2014;134(1):190-5.

19. Allen NE, Key TJ, Dossus L, et al. Endogenous sex hormones and endometrial cancer risk in women in the European Prospective Investigation into Cancer and Nutrition (EPIC). Endocr Relat Cancer. 2008;15(2):485-97.

20. Zakharov V, Lin HK, Azzarello J, et al. Suppressed expression of type 2 3alpha/type 5 17beta-hydroxysteroid dehydrogenase (AKR1C3) in endometrial hyperplasia and carcinoma. Int J Clin Exp Pathol. 2010;3(6):608-17.

21. Kamal AM, Bulmer JN, DeCruze SB, et al. Androgen receptors are acquired by healthy postmenopausal endometrial epithelium and their subsequent loss in endometrial cancer is associated with poor survival. $\mathrm{Br} \mathrm{J}$ Cancer. 2016;114(6):688-96

22. Gupta SP, Mittal A, Sathian B, et al. Elevated serum insulin is an independent risk factor for hepatocellular carcinoma: a case control study from Nepal. Asian Pac J Cancer Prev. 2013;14(12):7331-3.

23. Petridou ET, Sergentanis TN, Antonopoulos CN, et al. Insulin resistance: an independent risk factor for lung cancer? Metabolism. 2011;60(8):1100-6.

24. Wang $Y$, Zhu $Y$, Zhang L, et al. Insulin promotes proliferation, survival, and invasion in endometrial carcinoma by activating the MEK/ERK pathway. Cancer Lett. 2012;322(2):223-31.

25. Wang Y, Hua S, Tian W, et al. Mitogenic and anti-apoptotic effects of insulin in endometrial cancer are phosphatidylinositol 3-kinase/Akt dependent. Gynecol Oncol. 2012;125(3):734-41.

26. McCance KL, Jones RE. Estrogen and insulin crosstalk: breast cancer risk implications. Nurse Pract. 2003;28(5):12-23, 24-5.

27. Eritja N, Mirantes C, Llobet D, et al. Long-term estradiol exposure is a direct mitogen for insulin/EGF-primed endometrial cells and drives PTEN loss-induced hyperplasic growth. Am J Pathol. 2013;183(1):277-87.

28. Holm NS, Glintborg D, Andersen MS, et al. The prevalence of endometrial hyperplasia and endometrial cancer in women with polycystic ovary syndrome or hyperandrogenism. Acta Obstet Gynecol Scand. 2012;91(10):1173-6.

29. Dumesic DA, Lobo RA. Cancer risk and PCOS Steroids. 2013;78(8):782-5.

30. McGrath M, Lee IM, Hankinson SE, et al. Androgen receptor polymorphisms and endometrial cancer risk. Int J Cancer. 2006;118(5):1261-8.

31. Yang HP, Garcia-Closas M, Lacey JJ, et al. Genetic variation in the androgen receptor gene and endometrial cancer risk. Cancer Epidemiol Biomarkers Prev. 2009;18(2):585-9.

32. $\mathrm{Xu} \mathrm{W}$, Morford J, Mauvais-Jarvis F. Emerging role of testosterone in pancreatic beta-cell function and insulin secretion. J Endocrinol. 2019; [Epub ahead of print].
33. Mishra JS, More AS, Kumar S. Elevated androgen levels induce hyperinsulinemia through increase in Ins1 transcription in pancreatic beta cells in female rats. Biol Reprod. 2018;98(4):520-31.

34. Brettenthaler N, De Geyter C, Huber PR, et al. Effect of the insulin sensitizer pioglitazone on insulin resistance, hyperandrogenism, and ovulatory dysfunction in women with polycystic ovary syndrome. J Clin Endocrinol Metab. 2004;89(8):3835-40.

35. Moran C, Huerta R, Conway-Myers BA, et al. Altered autophosphorylation of the insulin receptor in the ovary of a woman with polycystic ovary syndrome. Fertil Steril. 2001;75(3):625-8.

36. Wang Y, Kreisberg JI, Ghosh PM. Cross-talk between the androgen receptor and the phosphatidylinositol 3-kinase/Akt pathway in prostate cancer. Curr Cancer Drug Targets. 2007;7(6):591-604.

37. Hamzeh M, Robaire B. Androgens activate mitogen-activated protein kinase via epidermal growth factor receptor/insulin-like growth factor 1 receptor in the mouse PC-1 cell line. J Endocrinol. 2011;209(1):55-64.

38. Wu JD, Haugk $\mathrm{K}$, Woodke $\mathrm{L}$, et al. Interaction of IGF signaling and the androgen receptor in prostate cancer progression. J Cell Biochem. 2006;99(2):392-401

39. Tian W, Teng F, Zhao J, et al. Estrogen and insulin synergistically promote type 1 endometrial cancer progression. Cancer Biol Ther. 2017;18(12):1000-10.

40. Tian W, Teng F, Gao J, et al. Estrogen and insulin synergistically promote endometrial cancer progression via crosstalk between their receptor signaling pathways. Cancer Biol Med. 2019;16(1):55-70. 